\title{
Identificação de Demanda e Preferências no Consumo de Carne Ovina com Apoio de Técnicas de Estatística Multivariada ${ }^{1,2}$
}

\author{
Ricardo Firetti ${ }^{3}$, Ana Lucia Luz Alberti ${ }^{4}$, Marilice Zundt ${ }^{5}$, \\ Antônio Assiz de Carvalho-Filho ${ }^{6}$ e Eduardo Cardoso de Oliveira ${ }^{7}$
}

Resumo: Este trabalho visa comprovar a existência de mercado para a carne ovina em cidades médias próximas a Presidente Prudente (mercado regional) e a percepção desses consumidores sobre os produtos que adquirem. Foram entrevistados 3.249 pessoas em oito cidades médias próximas utilizando-se formulários implementados em dispositivos portáteis. Investigou-se a frequência de consumo (atual e potencial) e opiniões sobre as características da carne ovina, e preferências de aquisição e consumo. Parte dos dados obtidos, referentes aos consumidores de carne ovina, foi tabulada e submetida a testes de validação e consistência interna; técnicas de estatística descritiva e multivariada. Do total de pessoas entrevistadas, $38,5 \%$ foram considerados consumidores de fato. O estudo comprovou que existe grande demanda de carne ovina nos municípios analisados em consumo domiciliar mensal, preferencialmente, na forma assada (68,5\% na brasa e 18,8\% no forno). A aquisição de produtos sem garantias oficiais de inspeção continua elevada, sendo que os supermercados apresentaram os piores níveis de satisfação em relação ao preço praticado (ao contrário da compra direta do produtor), mas, mesmo assim, este canal de comercialização de varejo é reconhecido como fornecedor de produtos seguros do ponto de vista higiênico-sanitário.

Palavras-chaves: agronegócio, cordeiro, análise de correspondência, marketing.

1. Os autores agradecem o financiamento da pesquisa pela Fapesp (Fundação de Amparo à Pesquisa do Estado de São Paulo) - processo 2011/23142-0.

2. Data de submissão: 3 de novembro de 2015. Data de aceite: 20 de julho de 2017.

3. Agência Paulista de Tecnologia dos Agronegócios/Secretaria de Agricultura e Abastecimento (Apta/ SAA/SP). Presidente Prudente, São Paulo, Brasil. E-mail: rfiretti@apta.sp.gov.br

4. Agência Paulista de Tecnologia dos Agronegócios/Secretaria de Agricultura e Abastecimento (Apta/ SAA/SP). Presidente Prudente, São Paulo, Brasil. E-mail: albertivet@apta.sp.gov.br

5. Universidade do Oeste Paulista (Unoeste). Presidente Prudente, São Paulo, Brasil. E-mail: mari@unoeste.br

6. Universidade Estadual Paulista "Júlio de Mesquita Filho" (Unesp). Presidente Prudente, São Paulo, Brasil. E-mail: assiz@fct.unesp.br

7. Bolsista FAPESP na Agência Paulista de Tecnologia dos Agronegócios/Secretaria de Agricultura e Abastecimento (Apta/SAA/SP). Presidente Prudente, São Paulo, Brasil. E-mail: aedzo@terra.com.br 


\begin{abstract}
This work aims to prove the existence of a market for sheep in medium-sized cities near Presidente Prudente, São Paulo (regional market), and the perception of these consumers on the products they purchase. A total of 3,249 people were interviewed in eight medium-sized cities using forms implemented in portable devices. The frequency of consumption (current and potential) and opinions on the characteristics of sheep meat, and preferences of acquisition and consumption were investigated. Part of the data obtained on sheep meat consumers was tabulated and subjected to validation tests and internal consistency; techniques of descriptive and multivariate statistics. From the total number of people interviewed, 38.5\% were considered consumers. The study showed that there is a great demand for sheep meat in the municipalities analyzed in monthly household consumption, preferably in roasted form (68.5\% in the coals and $18.8 \%$ in the oven). The purchase of products without official guarantees of inspection continues to be high, with supermarkets presenting the worst levels of satisfaction in relation to the price practiced (as opposed to the direct purchase of the producer). However, even so, this retail marketing channel is recognized as a supplier of hygiene-sanitary products.
\end{abstract}

Key-words: agribusiness, correspondence analysis, lamb, marketing.

Classificação JEL: Q13.

DOI: http://dx.doi.org/10.1590/1234-56781806-94790550404

\section{Introdução}

A cadeia produtiva da ovinocultura de corte pode ser considerada em transição de uma atividade modernizada, dependente do fornecimento de insumos, mas sem estabelecer vínculos específicos "antes e depois da porteira", para um complexo agroindustrial incompleto em que há alguma vinculação com a agroindústria de beneficiamento e/ou processamento (frigoríficos), conforme descrito por Farina e Zylbersztain (1991). Seguindo os pressupostos determinados pelos autores, a ovinocultura de corte poderia ser classificada quanto ao seu grau de maturidade como Cadeia do Tipo 3, pois não se percebe de maneira clara a demanda do consumidor, tratando-se da tipologia de cadeia produtiva menos estruturada.

Barreto Neto (2010) já apontava que a carne ovina estava conquistando consumidores dos centros urbanos e na região Sudeste, algo também observado por Ramos et al. (2014). Para os primeiros autores, o fato de o produto passar a ser ofertado em mercados mais dinâmicos evidenciaria oportunidades que precisariam ser melhor compreendidas e exploradas para que esta atividade pudesse atingir todo o seu potencial.

Para Decker et al. (2016), o aproveitamento dessas oportunidades pressupõe o delineamento de estratégias competitivas eficazes pelos agentes da cadeia produtiva, especialmente no que se refere à redução de custos de produção e oferta de produtos requisitados pelos consumidores. Os níveis de carne ovina demandados pelo mercado consumidor acima da oferta desses produtos determinaram a necessidade de importações (VIANA et al., 2015) que, segundo Barchet e Freitas (2012), constituem-se em ferramenta para equilibrar o mercado e possibilitar a oferta de carne com preço mais acessível.

No entanto, o principal desafio do setor produtivo residiria na sua capacidade de criar oferta de produtos cárneos ovinos para diferentes mercados, desde nichos altamente especializados, tais como a alta gastronomia, e mercados de amplo consumo, como a classe média brasileira (VIANA et al., 2013). A opinião do consumidor final poderia ser fundamental ao sistema produtivo da carne ovina no Brasil, por teoricamente determinar as características de maior importância da carne através da satisfação que o produto lhe proporciona.

Outro fator preponderante e que merece atenção está relacionado ao abate dos animais. No ambiente institucional da cadeia produtiva da ovinocultura de corte, problemas relacionados ao abate sem o devido acompanhamento de fiscalização de órgãos de vigilância sanitária (municipal, estadual ou federal) podem comprometer a qualidade da carne ovina, além de 
apresentar riscos à saúde e à confiança dos consumidores e, além de exercer forte influência sobre a cadeia de negócios como um todo, qualquer ação sobre ela causa impactos, positivos ou negativos, significativos em todo o sistema (RAMOS et al., 2014).

Em razão de uma parcela de consumidores que optam pela carne proveniente de abate clandestino, ao percebê-la como produto "caipira", originado direto do produtor, e que trazem consigo o sentimento de "volta às origens", negligenciando aspectos sanitários relacionados ao alimento, a informalidade do abate de ovinos ganhou status de garantia de origem e procedência em centros urbanos e cidades médias (SORIO, 2013). Tal situação foi observada no município de Maringá (PR) em trabalho realizado por Bankuti et al. (2013). Em Presidente Prudente (SP), estima-se que $45 \%$ dos consumidores de carne ovina adquiriam o produto diretamente do produtor rural (FIRETTI et al., 2011).

Estimativas do IBGE apontam que o País possuía, em 2015, cerca de 18,1 milhões de ovinos, e praticamente $60 \%$ do efetivo do rebanho nacional concentrava-se na região Nordeste (mais de 11 milhões de cabeças), seguido pela região Sul, com $27 \%$ dos animais (IBGE, 2016). Em relação aos estados, destacam-se o Rio Grande do Sul (21,5\%); a Bahia (17,2\%); Pernambuco $(13,1 \%)$ e Ceará $(12,5 \%)$. O estado de São Paulo, maior mercado consumidor de carnes do País por concentrar mais de 21 milhões de habitantes na região metropolitana de sua capital, aparecia apenas na $10^{a}$ posição do ranking de rebanho ovino nacional, com 385.853 cabeças ( $2,1 \%$ do total).

Claramente os produtores de carne ovina em São Paulo encontram vantagens operacionais e de logística pela sua localização geográfica em relação a fornecedores de outros estados, justamente pela proximidade ao expressivo mercado consumidor da capital. Em tese, quanto mais próximo da capital, maiores as vantagens de logística e melhor o acesso a segmentos de mercado de alto valor. Entretanto, mesmo neste estado, segundo dados do IBGE (2016), a concentração do rebanho ovino está localizada relativamente distante da capital, nas mesorregiões de São José do Rio Preto (17,4\% do rebanho paulista); Presidente Prudente (11\%); Araçatuba (10\%) e Bauru (10\%).

Em estudo prospectivo realizado pelo Departamento de Gestão Estratégica (DGE) da Agência Paulista de Tecnologia dos Agronegócios (Apta), órgão da Secretaria de Agricultura e Abastecimento do estado de São Paulo (BEZERRA et al., 2010), a ovinocultura de corte foi apontada como uma das principais atividades que visam a geração de renda para as pequenas e médias propriedades rurais da região de Presidente Prudente. Desta maneira, sugeriu-se a priorização de ações de pesquisa e desenvolvimento relacionadas à produção de carne ovina, e estudos mercadológicos em âmbito local (FIRETTI e BONACELLI, 2013).

Tal resultado foi a motivação para a realização de um estudo mercadológico que pudesse nortear o delineamento de sistemas de produção animal em função de produtos de carne ovina de interesse dos consumidores que residissem em cidades médias, com populações entre 100.000 e 500.000 habitantes (SOUZA et al., 2007), que estivessem distantes até $350 \mathrm{~km}$ de Presidente Prudente.

Desta forma, o presente trabalho objetivou comprovar a existência de mercado para a carne ovina em cidades médias próximas a Presidente Pudente (mercado regional), verificar a percepção dos consumidores sobre os produtos que adquirem e suas preferências de consumo quanto às características da carne, local de compra e forma de preparo.

\section{Procedimentos metodológicos}

O estudo teve a microrregião geográfica de Presidente Prudente (SP) como epicentro de abrangência, sendo investigadas oito cidades, consideradas médias, com populações variando de 150.000 a 350.000 habitantes, em três estados: São Paulo (SP), Mato Grosso do Sul (MS) e Paraná (PR). Os municípios foram: Araçatuba (SP), Bauru (SP), Dourados (MS), Londrina (PR), Marília (SP), Maringá (PR), Presidente Prudente (SP) e São José do Rio Preto (SP) (Figura 1). Os dados foram obtidos por meio de levantamentos in loco, entre setembro de 2012 e março de 2014.

Foram entrevistados 3.249 pessoas em idade superior a 15 anos entre janeiro e junho de 2013. As coletas se realizaram em locais de grande fluxo, regiões centrais e terminais urbanos, caracterizando a amostra como probabilística não proporcional, e atingindo o mínimo de 400 entrevistados por município. O questionário foi aplicado numa primeira fase em pré-teste no município de Presidente Prudente (SP) para correção de problemas de falta de clareza na colocação das questões para o consumidor. 
Figura 1. Localização geográfica das cidades investigadas

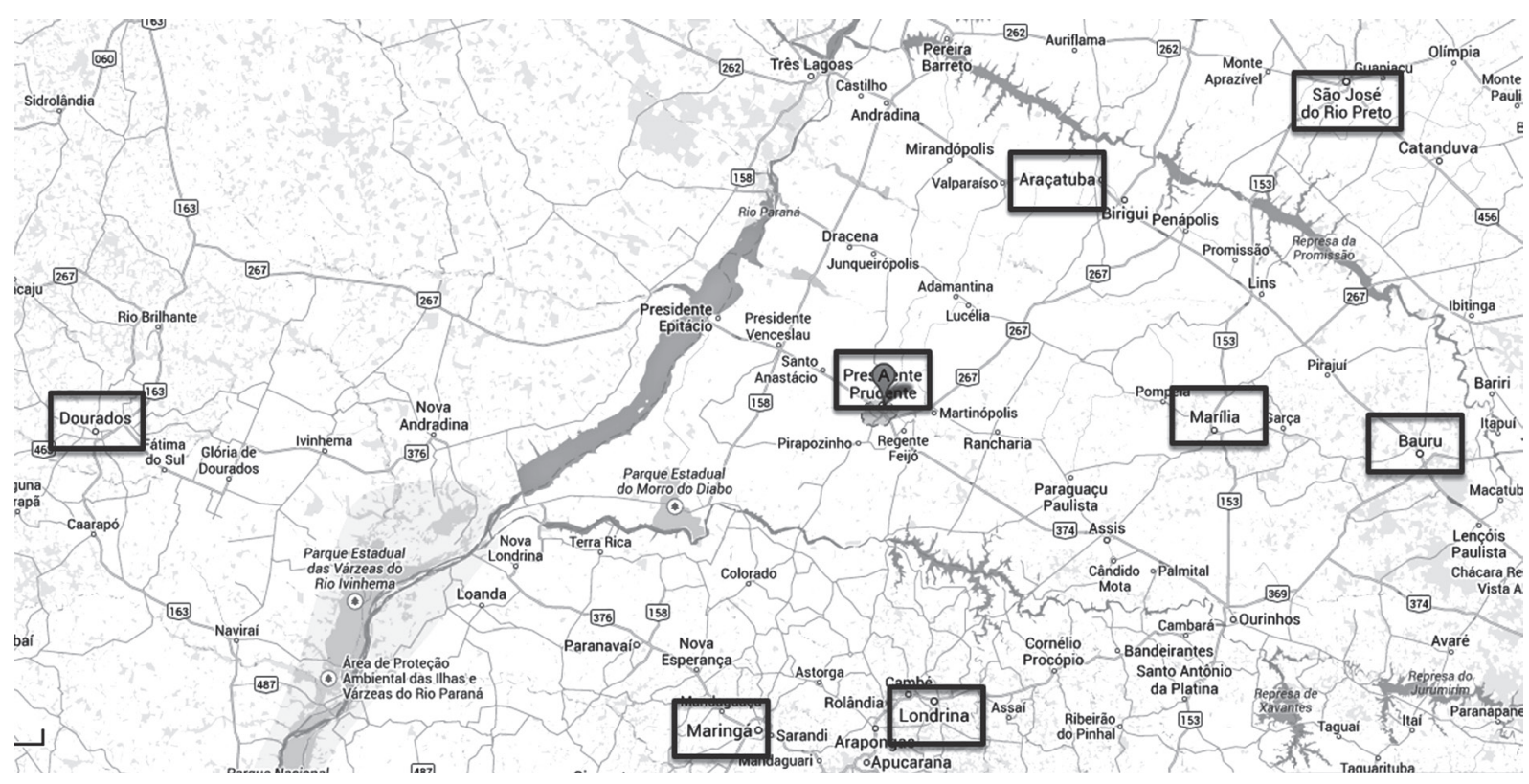

Fonte: Adaptado de Google Inc. (2014).

Para tanto, utilizam-se dispositivos portáteis como instrumentos de coleta (Tablet Galaxy S 5.0 com sistema Android versão 4.0) ao invés de formulários em papel com formulários eletrônicos, o que facilitou o levantamento e reduziu a subjetividade de algumas perguntas, haja vista a possibilidade de visualização de imagens ilustrativas de alta resolução pelos respondentes. $\mathrm{O}$ questionário foi estruturado em linguagem WEB, com programação em PHP e base de dados SQLite versão 3,0 que é nativo do sistema operacional Android.

Os formulários foram constituídos por 28 perguntas fechadas visando possibilitar a caracterização do perfil da pessoa respondente (sexo, idade, escolaridade e renda familiar); preferências em relação a diferentes tipos de carnes (bovina, suína, aves, pescado e ovina); frequência de consumo estimada de carne ovina (atual e potencial); a coleta de opiniões sobre características da carne ovina (cor, sabor, maciez, suculência e gordura); formas de preparo e consumo preferencial; grau de cozimento da carne; local onde geralmente consome a carne; valor nutricional, segurança alimentar e grau de satisfação com a disponibilidade, local de aquisição, e preço de produtos adquiridos. Em algumas questões foi utilizada uma de 5 pontos visando categorizar as respostas.
As variáveis observadas foram:

a) Perfil do consumidor: variável (Var) $1=$ ocupação principal; Var2 = sexo; Var3 = idade (anos); Var4 = nível de escolaridade; Var5 = renda familiar (salários mínimos); Var6 = residência no município;

b) Quanto ao consumo de carnes: Var7 = gosta de carne de ovinos (sim/não); Var8 = já experimentou a carne alguma vez; Var9 = já ouviu falar sobre esse tipo de carne; Var10 = interesse em experimentar a carne; Var11 = principal motivo por não ter gostado da carne; Var12 = dois tipos de carne que mais prefere; $\operatorname{Var} 13=$ frequência que consome carne de carneiro/cordeiro; Var14 = frequência que gostaria de consumir; Var15 = forma de preparo preferencial para a carne de carneiro/cordeiro; Var16 = local onde geralmente consome este tipo de carne;

c) Preferência em relação à carne ovina (escala de 1 a 5): Var17 = ponto de cozimento que prefere para comer carne de carneiro/cordeiro (INTERMEZZO GOURMET, 2012); Var18 = preferência em relação ao sabor; Var19 = preferência em relação à maciez; Var20 = preferência em relação à suculência; Var21 = preferência em relação à quantidade de gordura; 
d) Aquisição da carne ovina: Var22 = onde compra (ou compraria), preferencialmente, a carne de ovinos; Var23 = compra carne de carneiro ou cordeiro/carne em geral aqui no município de coleta; Var24 = satisfação com a disponibilidade/facilidade de encontrar produtos de carne de carneiro/cordeiro; Var25 = satisfação com o preço de venda dos produtos de carne de carneiro/cordeiro;

e) Opinião sobre a carne ovina (escala de 1 a 5): Var26 = considera a carne ovina saudável do ponto de vista digestivo e nutricional; Var27 = carne de carneiro/cordeiro que adquire é segura do ponto de vista higiênico e sanitário e confia no produto que consume.

Os dados obtidos no levantamento foram submetidos a testes de consistência interna e validação medidos pelo Alfa de Crombach e Kaiser's Measure of Sampling Adequacy (MSA). Posteriormente, foram analisados por meio de técnica descritiva utilizando a distribuição de frequências percentuais (GIL, 2012) e técnicas de estatística multivariada (BENZÉCRI, 1992; HAIR et al., 2009) descritas a seguir:

a) Análise fatorial por componentes principais: rotação ortogonal Varimax raw; escolha do número de fatores em função de Autovalores acima de 1,0; loading scores de 0,$44 ; b$ ); os fatores serão nomeados e analisados de maneira independente.

b) Análise de Correspondência (AC): realizada a partir do cruzamento entre variáveis do mesmo fator utilizando gráficos para melhor visualização. As principais correspondências identificadas entre as classes de resposta das variáveis foram sinalizadas por box com bordas vermelhas ao redor do agrupamento. Em alguns gráficos aparecem apontamentos (seta na cor preta) que denotam a tendência de correspondência (subjetivo).

\section{Resultados e discussão}

A amostra de 3.249 questionários foi composta por $27,6 \%$ de pessoas que não têm interesse em comer ou adquirir carne ovina (Desinteressados); 33,8\%, de Potenciais Consumidores, ou seja, pessoas que não têm hábito de consumo e manifestaram interesse ou curiosidade em experimentar produtos baseados em carne ovina; e 38,5\% (1.253 pessoas) que são os atuais Consumidores por terem algum hábito (mesmo que mínimo) de consumir carne ovina.

Do total de Desinteressados, $57 \%$ já haviam experimentado a carne e, da parcela que de fato não aprecia carne ovina, 65\% eram desmotivados pelo sabor da carne.

Quanto aos Consumidores, em torno de $22 \%$ indicaram ter o hábito de consumir carne ovina menos de uma vez/ano; $22,7 \%$, anualmente; $19,6 \%$, semestralmente ( 2 vezes/ano); 20,8\%, mensalmente; $8,7 \%$, quinzenalmente e apenas $4 \%$, semanalmente. Os que declaram não ter o hábito regular de consumir carne ovina somam cerca de $1,7 \%$. Os resultados apontam semelhanças ao observado em pesquisa realizada por Firetti et al. (2011) para o estado de São Paulo, com ênfase na capital paulista, no qual foi observado que $40,2 \%$ dos consumidores comiam carne ovina entre 1 e 2 vezes/ano (44,3\% na pesquisa atual); embora as demais distribuições sejam diferentes.

Neste caso, o aspecto mais relevante é quando se compara o atual consumo aparente dos Consumidores com a frequência na qual gostariam de consumir (Figura 2). Praticamente ocorre uma inversão na escala de frequências, em que $27,4 \%$ consumiriam semanalmente; $28 \%$, quinzenalmente; $20 \%$, mensalmente; $9,2 \%$, até duas vezes ao ano; apenas $7 \%$ consumiriam anualmente e $4 \%$, menos de uma vez ao ano. Esses resultados comprovam que existe demanda de carne ovina reprimida nos mercados observados com espaço para crescimento da oferta adequada de produtos.

Levantamento realizado em Sobral (CE) (CARVALHO et al., 2016), com 385 indivíduos, apontou que cerca de $74,5 \%$ das pessoas entrevistadas afirmaram adquirir carne ovina para consumo, índices muito superiores aos encontrados neste trabalho $(38,5 \%)$. Os autores observaram, ainda, que $35,4 \%$ dos consumidores compravam carne ovina pelo menos uma vez ao mês. Firetti et al. (2010) encontraram percentuais parecidos no mercado consumidor da capital paulista, mas para a frequência de 1 vez/ano.

As respostas de 1.253 informantes para 14 questões selecionadas foram submetidas aos testes de Alfa de Crombach $(0,64)$ e MAS $(0,73)$. Na Análise Fatorial foram extraídos cinco fatores, correspondendo a $55,32 \%$ da variância total dos dados que, segundo Hair et al.(2009), seria suficiente em pesquisas exploratórias (Tabela 1). 
Figura 2. Distribuição de número de respostas sobre qual frequência que gostaria de consumir carne ovina (Variável 14)

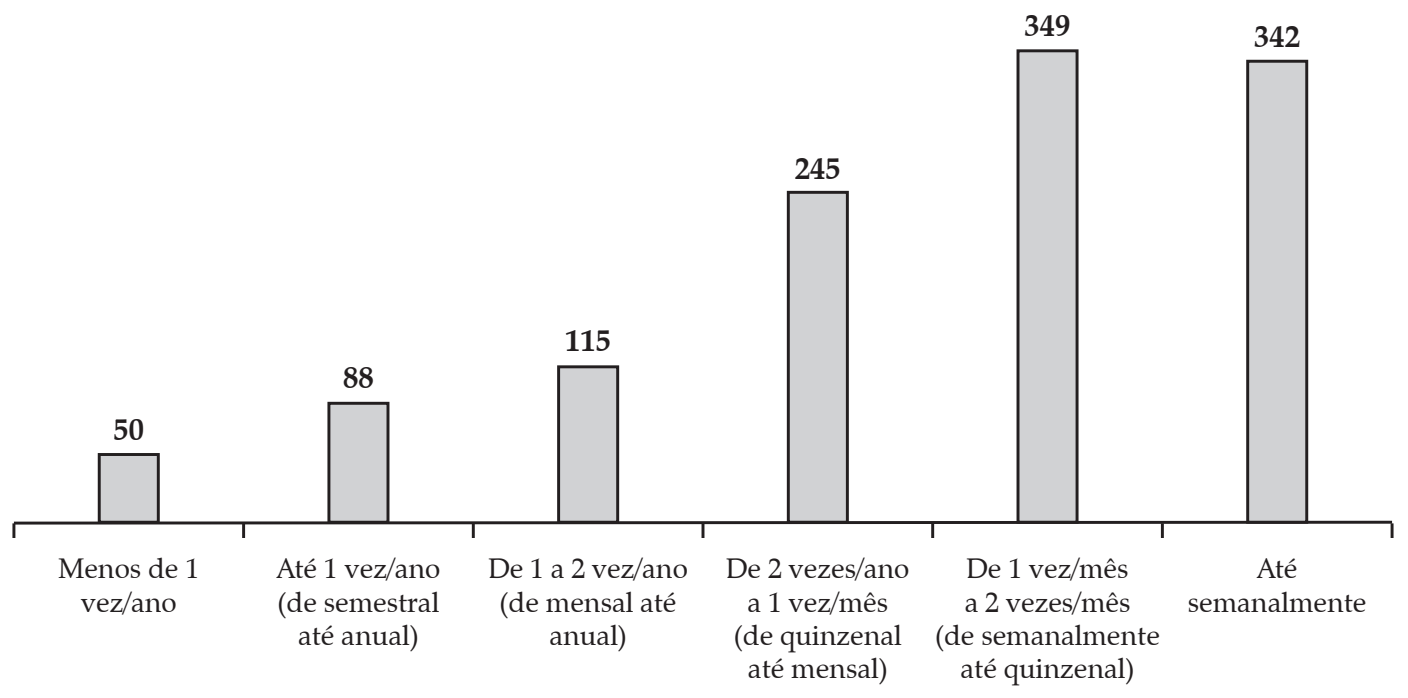

Fonte: Resultados da pesquisa.

Tabela 1. Fatores extraídos na análise estatística multivariada e correlação com as variáveis

\begin{tabular}{|c|c|c|c|c|c|}
\hline & Fator 1 & Fator 2 & Fator 3 & Fator 4 & Fator 5 \\
\hline Frequência de consumo atual & & 0.689 & 0.359 & -0.114 & \\
\hline Frequência de consume potencial & 0.162 & 0.716 & & & 0.126 \\
\hline Formas de preparo & 0.108 & 0.486 & -0.223 & & -0.501 \\
\hline Local que consome & & -0.235 & & 0.722 & \\
\hline Ponto de cozimento & & 0.446 & -0.102 & 0.379 & -0.440 \\
\hline Preferência de sabor & 0.214 & 0.330 & -0.107 & 0.499 & 0.215 \\
\hline Preferência de maciez & 0.695 & & & 0.269 & \\
\hline Preferência de suculência & 0.588 & 0.132 & & & 0.311 \\
\hline Preferência de gordura & 0.231 & 0.178 & & 0.178 & 0.680 \\
\hline Local de compra & & 0.184 & 0.335 & 0.476 & \\
\hline Satisfação com disponibilidade & 0.138 & 0.110 & 0.717 & & \\
\hline Satisfação com preço & 0.134 & & 0.768 & 0.108 & \\
\hline Considera a carne saudável & 0.772 & 0.150 & 0.125 & & \\
\hline Considera carne segura & 0.760 & & 0.126 & -0.137 & \\
\hline
\end{tabular}

* Valores em negrito indicam correlação da variável (linha) com o fator (coluna).

Fonte: Resultados da pesquisa.

\section{Fator 1: Características da carne}

O Fator 1 refere-se às características da carne ovina sob a percepção dos consumidores, reunindo as variáveis relacionadas a considerações sobre a carne ser saudável $(0,77)$ e segura $(0,76)$; sua maciez $(0,69)$ e suculência $(0,58)$; e o ponto de cozimento preferido $(0,44)$.

O aspecto mais marcante deste fator é que $62,5 \%$ dos consumidores entrevistados preferem o ponto de cozimento "bem passado", quando a carne está com- pletamente cozida e não apresenta qualquer pigmentação avermelhada.

Outra questão importante é que $61,7 \%$ concordaram totalmente com a afirmação de que a carne ovina é saudável do ponto de vista digestivo e nutricional.

$\mathrm{Na}$ análise de correspondência entre as variáveis "quanto considera a carne ovina saudável do ponto de vista digestivo e nutricional" (Variável 26) e "segurança do ponto de vista higiênico e sanitário" (Variável 27), foi possível observar forte relação entre a classe de reposta 
"Concordo Parcialmente" que a carne ovina é saudável, com as classes de resposta "Concordo Parcialmente" e, principalmente, "Discordo Parcialmente" que a carne é segura do ponto de vista higiênico e sanitário (Figura 3). Este fato traz à tona eventuais problemas mercado- lógicos para a parcela de consumidores que entende os benefícios nutricionais da carne ovina (e potencialmente é alvo de campanhas de marketing nesse sentido), mas não confia no produto que compra e/ou consome.

Figura 3. Correspondência entre as variáveis "considera a carne ovina saudável do ponto de vista digestivo e nutricional" (Variável 26) e "segurança do ponto de vista higiênico e sanitário" (Variável 27)

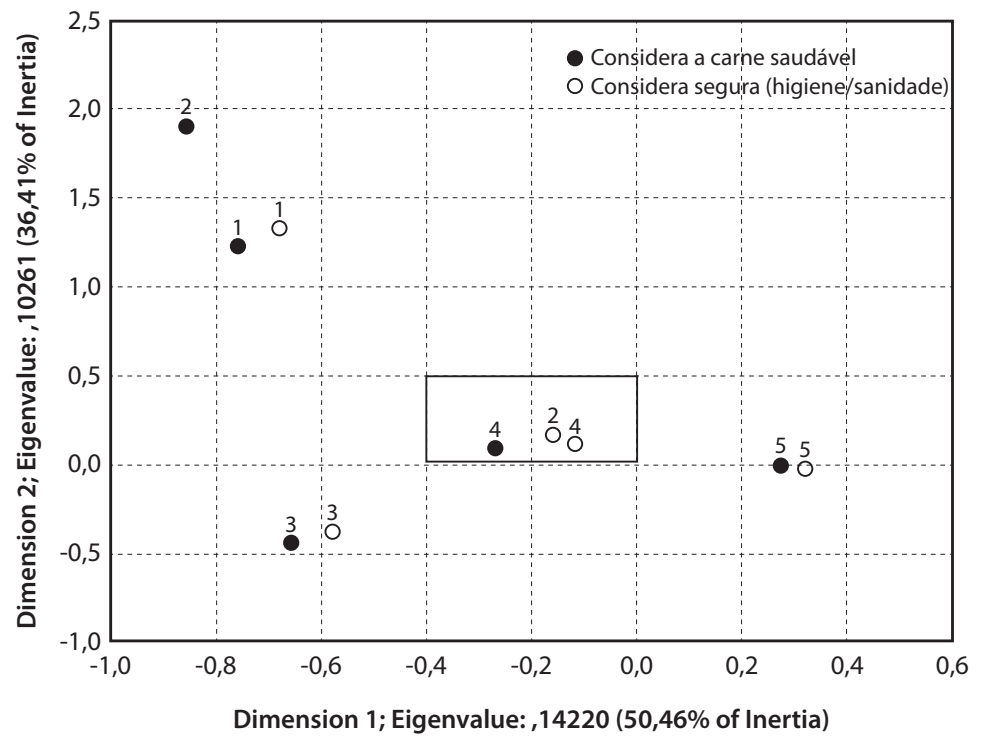

Legenda: 1. Discordo totalmente; 2. Discordo parcialmente; 3. Indiferente; 4. Concordo parcialmente; 5 . Concordo totalmente. Fonte: Resultados da pesquisa.

Figura 4. Correspondência entre as variáveis "onde compra ou compraria" (Variável 22) e "segurança do ponto de vista higiênico e sanitário" (Variável 27)

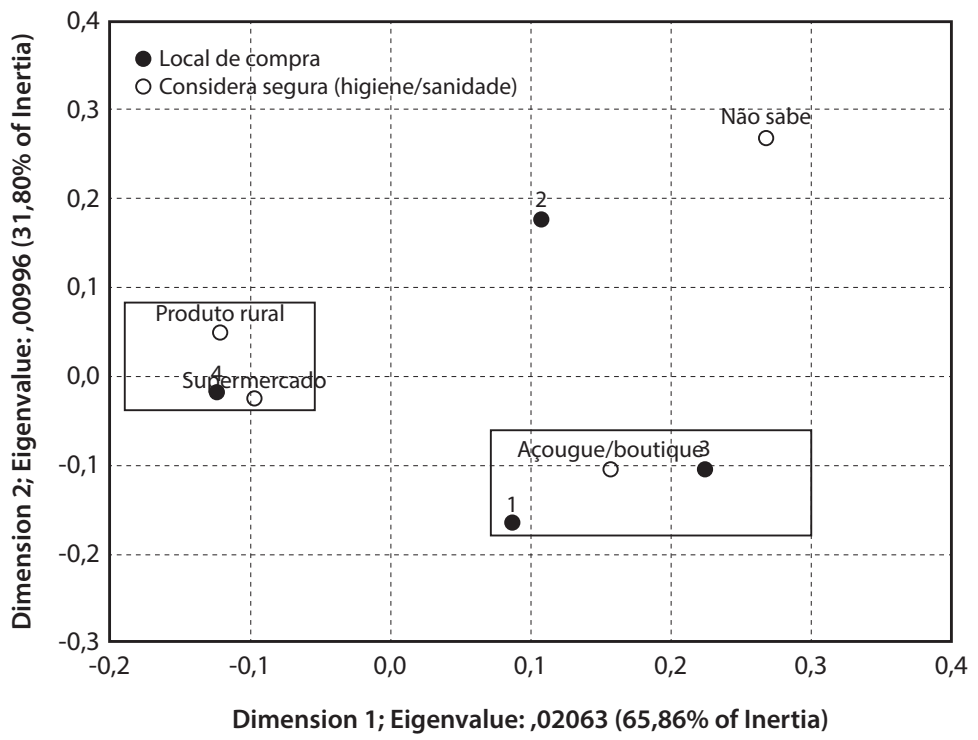

Legenda: 1. Discordo totalmente; 2. Discordo parcialmente; 3. Indiferente; 4 . Concordo parcialmente. Fonte: Resultados da pesquisa. 
Ao aprofundar esta questão a partir da análise de correspondência entre as variáveis "local de compra" da carne e de percepção quanto à "segurança do ponto de vista higiênico e sanitário" (Figura 4), é possível identificar que os consumidores que preferencialmente compram carne diretamente de produtores rurais e de supermercados concordam totalmente que a carne ovina que consomem é segura. O trabalho de Bánkuti et al. (2013) no município de Maringá (PR) tem resultados semelhantes, embora utilizando-se de metodologia diferente. Em contrapartida, existe uma correspondência entre níveis menores de segurança com os açougues e boutiques de carne, o que de certa forma aponta a preocupação de consumidores com os canais tradicionais de comercialização de carnes.

Todavia, o trabalho de Zundt et al. (2014) mostrou que carnes ovinas embaladas à vácuo e comercializadas em hipermercados no varejo de Presidente Prudente apresentaram presença de contagens relevantes de coliformes, o que aponta possíveis falhas nos procedimentos higiênico-sanitários, sendo que algumas amostras indicaram a "presença de Salmonella, bactéria que pode provocar graves danos à saúde, levando, inclusive, a óbito, além de ferir a legislação vigente que preconiza sua ausência".

\section{Fator 2: Hábitos de consumo}

O segundo fator correlaciona variáveis ligadas ao hábito de consumo das pessoas entrevistadas, sendo composto pelas variáveis de frequência de consumo potencial $(0,71)$ e atual $(0,68)$, e a forma de preparo preferencial $(0,48)$.

Em torno de 55,5\% das pessoas entrevistadas gostariam de consumir carne ovina pelo menos duas vezes no mês (quinzenalmente), sendo que a forma de preparo preferida é assada (87,3\%), utilizando os métodos de grelhados/assados na brasa $(68,5 \%)$, culturalmente denominado de "churrasco", e assado no forno $(18,8 \%)$.

A análise de correspondência entre as variáveis "frequência que gostaria de consumir" e "forma de preparo preferencial para a carne de carneiro/cordeiro" claramente associa três agrupamentos distintos em função da preferência de consumo (Figura 5), com destaque para as formas de preparo no domicílio, ou seja, que utilizam o fogão no preparo da carne e que correspondem principalmente às frequências de consumo mais periódico (até uma vez por mês). Por ter sido a opção de preparo mais relevante no levantamento, a classe de resposta "Grelhado/Assado na brasa" apre-

Figura 5. Correspondência entre as variáveis "frequência que gostaria de consumir" (Variável 14) e "forma de preparo preferencial para a carne de carneiro/cordeiro" (Variável 15)

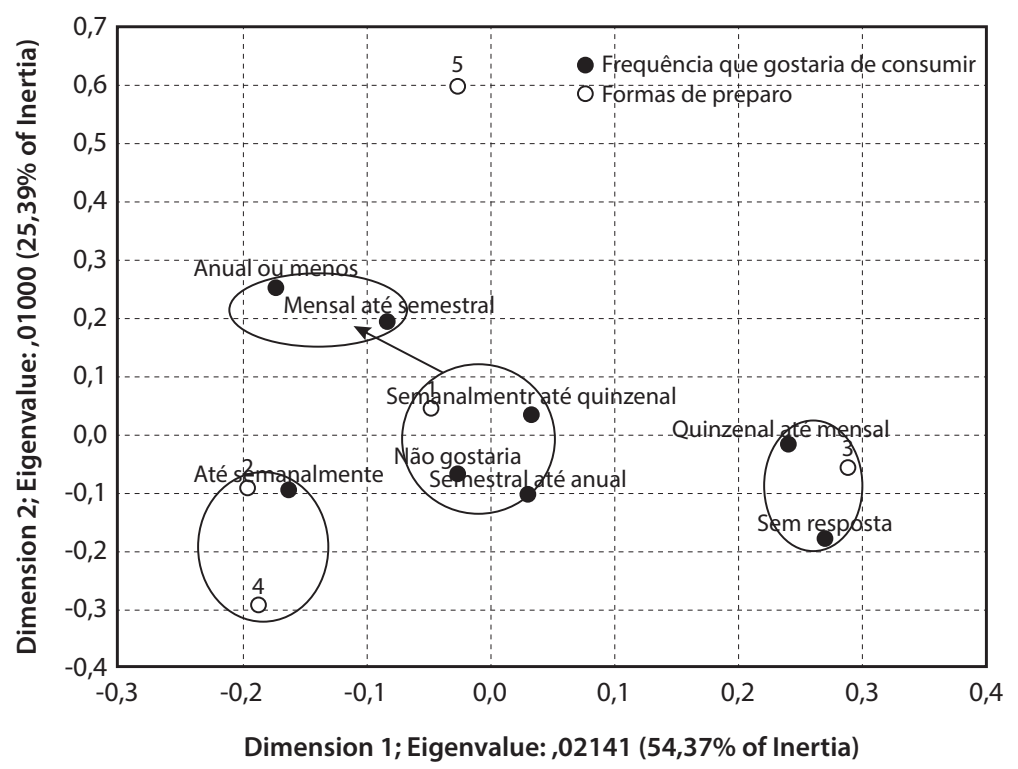

Legenda: 1. Assada na brasa (churrasco); 2. Frita ou grelhada (chapa); 3. Assada no forno; 4. Cozida/Refogada; 5 . Outra forma de preparo. Fonte: Resultados da pesquisa. 
senta correspondência com diferentes frequências de consumo, mas principalmente com as classes "Semanal a quinzenal", "Mensal a semestral" e "Anual a menos".

\section{Fator 3: Mercado Fornecedor}

No terceiro Fator destacaram-se as questões mercadológicas ligadas com a satisfação com preços $(0,76)$ e disponibilidade $(0,71)$. Nesse caso, os resultados apontam que apenas $19,7 \%$ dos consumidores estavam satisfeitos com os preços praticados pelo varejo, e $34,5 \%$ estavam satisfeitos com a disponibilidade de produtos.

Ao analisar o relacionamento entre os níveis de satisfação e o local preferencial de compra da carne ovina, foi possível observar problemas na estrutura da cadeia produtiva que remetem à classificação realizada por Farina e Zylbersztain (1991) quanto ao Tipo de Cadeia, por não se perceber de maneira clara a demanda do consumidor, e por possuir características de atividade modernizada. Na análise subsequente (Figura 6) percebe-se nitidamente a tendência dos melhores níveis de satisfação com a disponibilidade estarem relacionados à carne adquirida, respectivamente, no "Produtor Rural", "Açougue/Boutique", "Supermercado".
Quando se analisa a correspondência entre as variáveis "onde compra ou compraria" e "satisfação com o preço de venda dos produtos de carne de carneiro/cordeiro" (Figura 7), novamente a tendência de melhores níveis de satisfação é observada. Novamente chamam a atenção os "supermercados" corresponderem aos piores níveis de satisfação ("Totalmente Insatisfeitos").

$\mathrm{O}$ fato de os consumidores entrevistados apontarem maior satisfação (Totalmente Satisfeito") com o local de compra representado pelos "Produtores Rurais" reforça a tese de que a carne ovina ainda poderia estar associada a questões de boa origem e procedência. Ademais, a carne ovina tem preços no varejo considerados elevados para a capacidade de consumo em função da renda.

Lucena et al. (2008), em pesquisa realizada em Mato Grosso do Sul, observaram que a frequência de consumo de carne ovina foi considerada baixa e estaria provavelmente associada: ao preço elevado do produto, a pouca informação ao consumidor dos seus valores nutricionais e à diversidade de produtos substitutos disponíveis no varejo. Firetti et al. (2011) identificaram a baixa disponibilidade do produto e altos preços como principais aspectos negativos em Presidente Prudente, estado de São Paulo.

Figura 6. Correspondência entre as variáveis "onde compra ou compraria" (Variável 22) e "satisfação com a disponibilidade/facilidade de encontrar produtos de carne de carneiro/cordeiro" (Variável 24)

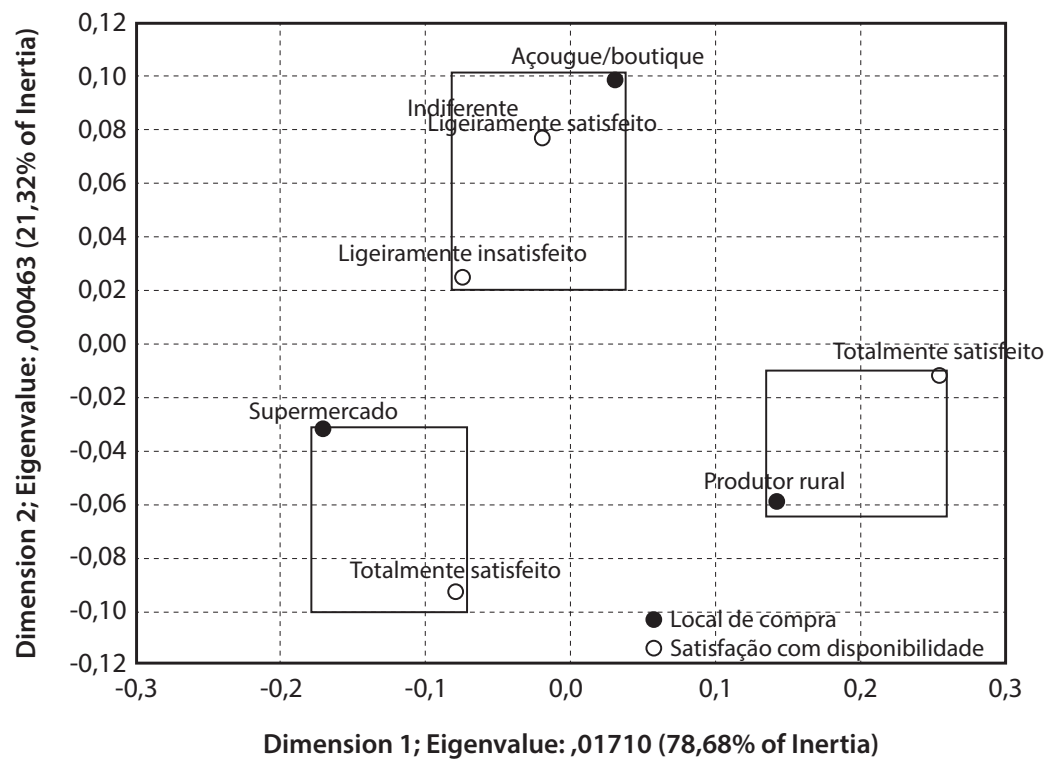

Fonte: Resultados da pesquisa. 
Figura 7. Correspondência entre as variáveis "onde compra ou compraria" (Variável 22) e "satisfação com o preço de venda dos produtos de carne de carneiro/cordeiro" (Variável 25)

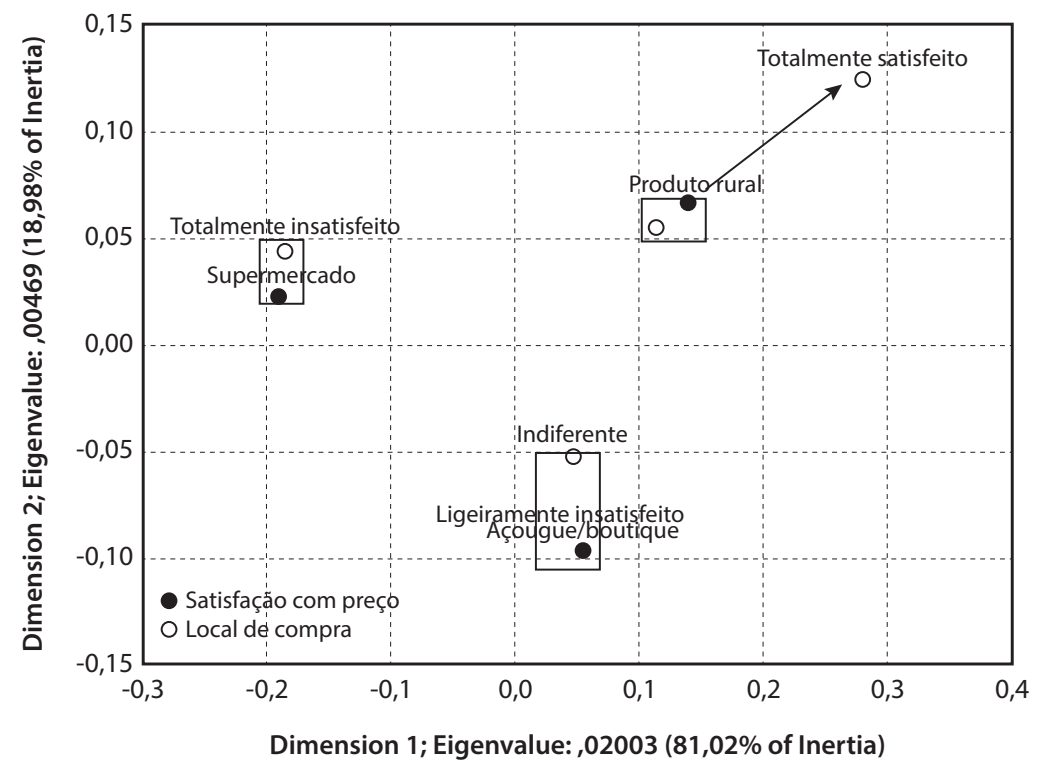

Fonte: Resultados da pesquisa.

\section{Fator 4: Aquisição e Consumo}

Ao quarto Fator, denominado locais de aquisição e consumo, destacam-se os locais de consumo da carne $(0,72)$ e compra $(0,47)$; e preferências em relação ao sabor $(0,49)$. Neste último quesito, $63 \%$ dos consumidores preferem carne com sabor suave e muito suave.

Os principais locais de consumo são no próprio domicílio (52,6\%) e na casa de parentes $(20,8 \%)$, sendo que o local de aquisição preferencial são os hipermercados $(30,3 \%)$ e açougues/boutiques de carne $(28,6 \%)$. Todavia, a aquisição de produtos sem abate inspecionado segue alta, pois $31 \%$ dos entrevistados afirmaram preferir comprar diretamente do produtor rural.

Os trabalhos anteriores de Firetti et al. $(2010,2011)$, em Presidente Prudente, e de Bánkut et al. (2013), em Maringá, traziam a informação dessa preferência em função de um mix de melhores preços, disponibilidade e sensação de "garantia de procedência".

Quando se procura correspondência nas respostas das variáveis "onde compra ou compraria" e "preferência em sabor", é possível identificar três agrupamentos de consumidores (Figura 8).

O primeiro agrupamento, e mais importante, é formado por pessoas que adquirem a carne ovina em
Açougue/Boutique ou diretamente do Produtor Rural com correspondência às preferências sobre o sabor suave e intermediário da carne (escalas 2 e 3, de 5).

No segundo agrupamento, observa-se a correspondência na aquisição de carne nos Supermercados e percepção sobre a preferência ao sabor muito intenso da carne (escala 5).

As perguntas de percepção dos consumidores sobre a preferência de sabor neste tipo de pesquisa são subjetivas, ao contrário de estudos objetivos a partir de análise sensorial de carne utilizando degustadores treinados, ou mesmo consumidores frequentes. No entanto, a percepção captada refere-se especialmente às experiências de consumo que, de alguma forma, agradaram aquele consumidor entrevistado, criando hábitos específicos.

$\mathrm{Na}$ análise de correspondência entre as variáveis "local onde geralmente consome este tipo de carne" e "frequência que gostaria de consumir" (Figura 9) é possível verificar a associação entre o consumo domiciliar e em restaurantes com a frequência (potencial) de consumo "semanal". Ou seja, os consumidores que já têm o hábito de preparar a carne ovina em sua própria residência principalmente corresponderiam à parcela que indicaram o desejo de consumi-la com muita frequência. 
Figura 8. Correspondência entre as variáveis "onde compra ou compraria" (Variável 22) e "preferência em sabor" (Variável 18)

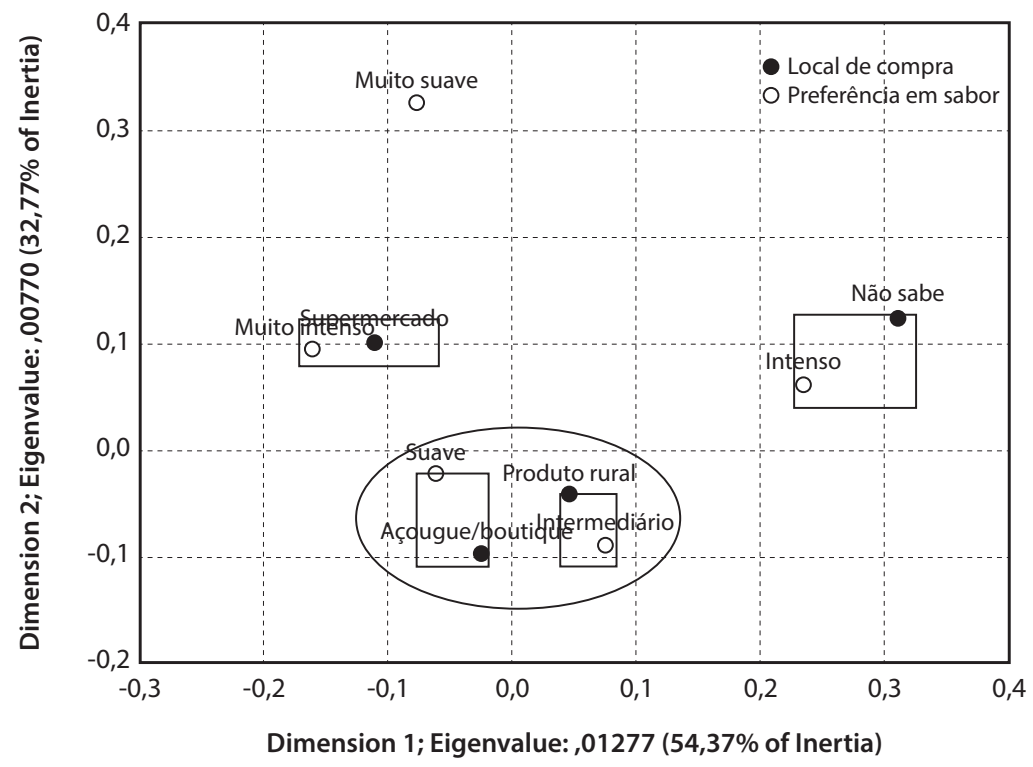

Fonte: Resultados da pesquisa.

Figura 9. Correspondência entre as variáveis "local onde geralmente consome este tipo de carne" (Variável 16) e "frequência que gostaria de consumir" (Variável 14)

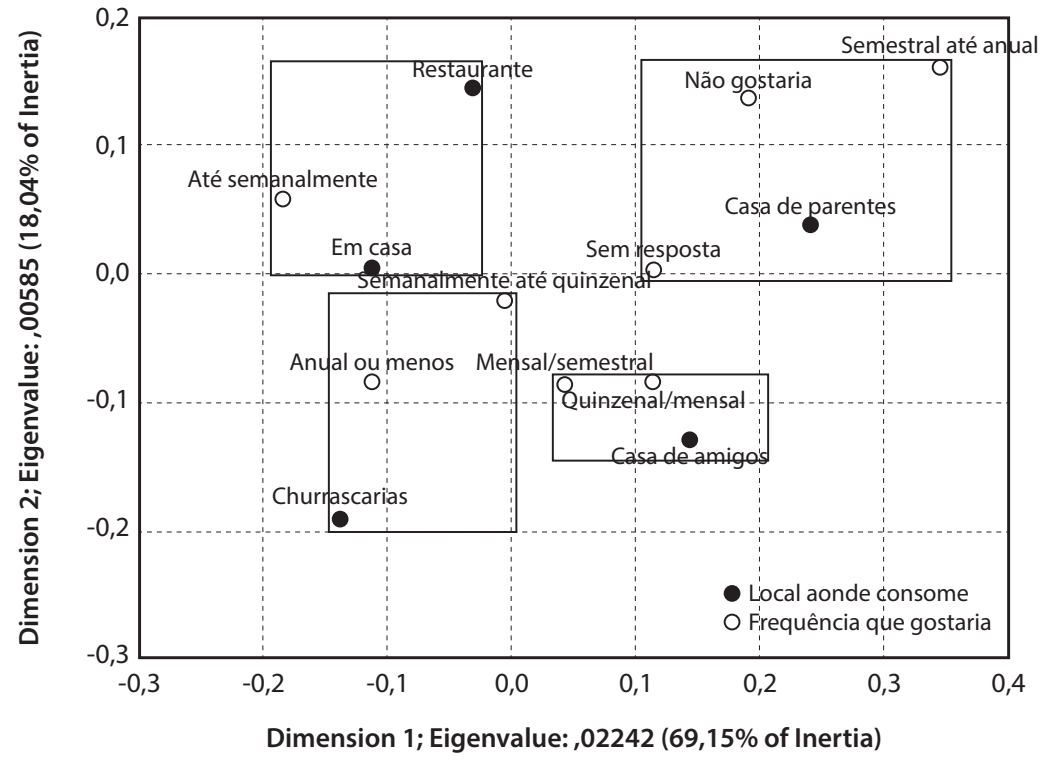

Fonte: Resultados da pesquisa.

\section{Fator 5: Resultado do Preparo}

É determinado pelas variáveis "forma de preparo" $(-0,50)$; "ponto de cozimento" $(-0,44)$ e "preferência pela quantidade de gordura na carne" $(0,68)$.
Embora a análise de correspondência entre as variáveis do Fator 5 não tenham apresentado agrupamentos interessantes, sob o ponto de vista analítico, ao associar a "preferência em relação à quantidade de gordura" com a "forma de preparo preferencial para a 
Figura 10. Correspondência entre as variáveis "preferência em relação à quantidade de gordura" e "forma de preparo preferencial para a carne de carneiro/cordeiro"

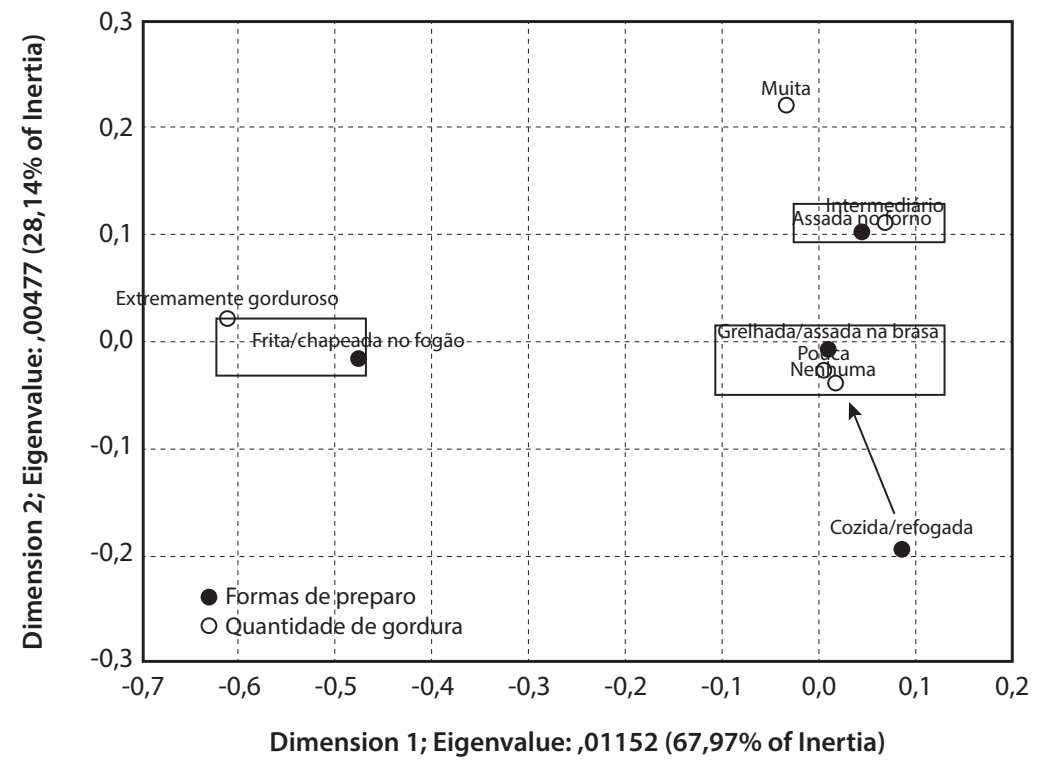

Fonte: Resultados da pesquisa.

carne de carneiro/cordeiro", foi possível observar três agrupamentos de correspondências que relacionam classes de respostas distintas e que chamam a atenção (Figura 10).

O primeiro agrupamento, mais relevante, é formado pela principal forma de preparo - Grelhada/ assada na brasa (68,5\% das respostas) - com as respostas: Pouca $(42,7 \%$ das repostas) ou Nenhuma quantidade de gordura (34,7\% das respostas). A forma de preparo Assada no forno (18,9\%) obteve interessante correspondência com o nível Intermediário de gordura $(13,65 \%)$.

De acordo com Góes et al. (2016), a má apresentação e o excesso de gordura nas carcaças e cortes cárneos são fatores que afetam a compra e a experiência de consumo de carne de ovinos. Para os autores, a deposição de gordura na carne ovina pode ser influenciada por fatores tais como: peso vivo ao abate, sexo do animal, dieta, genótipo e tipo de músculo. Entretanto, dentre essas variáveis, a dieta teria grande impacto sobre a deposição de gordura intramuscular, bem como sobre a concentração de ácidos graxos saturados e ácidos graxos poli-insaturados.

\section{Conclusões}

O estudo comprova que existe potencial de mercado para consumo de carne ovina na abrangência geográfica determinada, a partir do levantamento realizado nas cidades médias de Presidente Prudente, Araçatuba, Marília, Bauru, São José do Rio Preto, Dourados, Londrina e Maringá. Os resultados apontam demanda de consumo reprimida, seja pelo tipo de oferta ou preços praticados, pois cerca de $75 \%$ das 1.253 pessoas caracterizadas como Consumidores gostariam de consumir mensalmente esse produto, sendo que apenas $33,5 \%$ dessas pessoas afirmaram consumir mensalmente, diferença de $41,5 \%$ (ou 2,23 vezes mais) na intenção de consumo.

Os aspectos mais determinantes no hábito de consumo das pessoas entrevistadas foram que o principal local de consumo ocorria no domicílio $(73,4 \%)$, sendo $52,6 \%$ na própria residência e $20,8 \%$ na casa de parentes; e que a forma de preparo preferida foi o Assado $(87,3 \%)$, utilizando os métodos de cocção na brasa $(68,5 \%)$ e assado no forno $(18,8 \%)$, utilizando cortes magros. Chamou a atenção que $62 \%$ preferiam o ponto 
de cozimento "bem passado", quando o a carne está completamente cozida e não apresenta qualquer pigmentação avermelhada e carnes assadas com pouca e nenhuma gordura.

Quanto ao local de aquisição preferencial, os canais formais foram utilizados por $60 \%$ dos consumidores (hipermercados 30,3\%; e $28.6 \%$ em açougues/ boutiques de carne). Todavia, a aquisição de produtos sem abate inspecionado, embora menor que o obtido em estudo correlatos, continua relativamente alta, visto que $31 \%$ dos entrevistados afirmaram preferir comprar diretamente do produtor rural.

Nesse sentido, consumidores que preferencialmente compravam carne diretamente de produtores rurais e de supermercados concordaram totalmente que o produto que consumiam era seguro do ponto de vista higiênico e sanitário, conferindo ao primeiro local de compra o status de boa procedência. Outro fato encontrado é que os "supermercados" corresponderam aos piores níveis de satisfação ("Totalmente Insatisfeitos") em relação ao preço praticado, situação antagônica à aquisição no Produtor.

Assim, a ampliação do consumo poderia ser estimulada com estratégias mercadológicas relacionadas à: oferta de cortes cárneos simplificados destinados ao espeto ou grelha, redução de preços no varejo (aumento na competitividade), redução da oferta de carne sem inspeção oficial (o que poderia ocorrer por meio de normatização de procedimentos ao Produtor-fornecedor) e criação de campanhas de publicidade ratificando as qualidades nutricionais da carne ovina.

\section{Referências}

BÁNKUTI, F. I., BÁNKUTI, S. M. S. e MACEDO, F. A. A informalidade em sistemas agroindustriais: um estudo exploratório dos hábitos de consumo de carne ovina na cidade de Maringá, Estado do Paraná. Informações Econômicas, v. 43, n. 1, p. 5-17, 2013.

BARCHET, I. e FREITAS, C. A. Integração de preços entre o Rio Grande do Sul, Uruguai, Brasil e Austrália nos mercados da carne ovina e da lã. Espacios, Caracas, v. 33, n. 7, p. 5, 2012. Disponível em: <http://www. revistaespacios.com/a12v33n07/12330705.html>. Acesso em: 05 jan. 2013.

BARRETO NETO, A. D. Posicionamento estratégico do setor de carnes de caprinos e ovinos no mercado de carnes brasileiro. Tecnologia e Ciência Agropecuária, João Pessoa, v. 4, n. 4, p. 81-85, 2010.

BENZÉCRI, J.-P. Correspondence analysis handbook. New York: Marcell Dekker, 1992.

BEZERRA, L. M. C. et al. Desenvolvimento rural da Alta Sorocabana em São Paulo: uma contribuição através da prospecção de demandas. Revista Brasileira de Gestão e Desenvolvimento Regional, Taubaté, v. 6, n. 3, 2010.

CARVALHO, G.A. et al. Caracterização do mercado da carne ovina em Sobral, Estado do Ceará. Informações Econômicas, São Paulo, v. 46, n. 2, 2016.

DECKER, S. R. F., FERNANDES, D. A. C. e GOMES, M. C. Gestão Competitiva na Produção de Ovinos. Agropampa: Revista de Gestão do Agronegócio, v. 1, n. 1, 2016.

FARINA, E. Q. M. e ZYLBERSZTAJN, D. Relações tecnológicas e organização dos mercados do sistema agroindustrial de alimentos. Cadernos de Ciência E Tecnologia, v. 8, n. 1, p. 9-27, 1991.

FIRETTI, R. e BONACELLI, M. B. M. Mecanismos e resultados de ações regionais de pesquisa agrícola baseadas em estudos prospectivos. Revista de Economia Agrícola, São Paulo, v. 60, n. 2, p. 41-55, 2013.

. et al. Aspectos mercadológicos da carne ovina no município de Presidente Prudente, Estado de São Paulo. Informações Econômicas, v. 41, p. 5-18, 2011.

., CARRER, C. C. e SILVA, V. L. Percepção dos consumidores paulistas em relação a carne ovina: análise fatorial por componentes principais. Revista Brasileira de Saúde e Produção Animal, v. 11, n. 1, p. 1-13, 2010.

GIL, A. Método e técnicas de pesquisa social. 6. ed. São Paulo: Atlas, 2012. 200p.

GOIS, G. C. et al. Composição de ácidos graxos na carne ovina. Journal of Biology \& Pharmacy and Agricultural Management, João Pessoa, v. 12, n. 3, 17p., 2016.

HAIR, Jr., J. F. et al. Análise multivariada de dados. Trad. Adonai Schlup Sant'Anna. 6. ed. Porto Alegre: Bookman, 2009.

IBGE - Instituto Brasileiro de Geografia e Estatísticas. Pesquisa Pecuária Municipal 2015. Rio de Janeiro: IBGE, 2016

LUCENA, L. P. et al. Cadeia produtiva da ovinocultura em Mato Grosso do Sul: uma análise de seu sistema de coordenação agroindustrial. In: CONGRESSO BRASILEIRO DE ECONOMIA, ADMINISTRAÇÃO E SOCIOLOGIA RURAL, 46., 2008, Rio Branco. Anais... Brasília: SOBER, 2008. CD-ROM. 
RAMOS, M. J. et al. Sistema agroindustrial da carne ovina no Oeste paranaense. Revista de Política Agrícola, v. 23, n. 1, p. 18-32, 2014.

SORIO, A. A carne ovina e o abate clandestino: A informalidade tem jeito? Revista Cabra e Ovelha, n. 78, maio 2013.

SOUZA, M. V. M. et al. Reflexões sobre o conceito de cidade média e a configuração das estruturas comerciais varejistas e de serviços: o caso do bairro Planalto em Uberlândia (MG). In: X SIMPÓSIO NACIONAL DE
GEOGRAFIA URBANA. Anais... Florianópolis: UFSC, 2007. p. 01-21.

VIANA, J. G. A., REVILLION, J. P. P. e SILVEIRA, V. C. P. Alternativa de estruturação da cadeia de valor da ovinocultura no Rio Grande do Sul. Revista Brasileira de Gestão e Desenvolvimento Regional, Taubaté, v. 9, n. 1, p. 187-210, 2013.

ZUNDT, M. et al. Qualidade microbiológica e química da carne de ovinos de duas diferentes procedências comercializada em Presidente Prudente-SP. Colloquium Agrariae, v. 10, n. 2, p. 75-83. 